\title{
Modelling and Analysis of Compound Tool for Vee-Cap
}

\author{
Asif Afzal ${ }^{l}$, Mohammed Faheem ${ }^{l}$, Mohammed Jasil ${ }^{l}$, Ali Afzal ${ }^{l}$ \\ ${ }^{\prime}$ (Mechanical Engineering Department, P. A. College of Engineering, Mangalore, India)
}

\begin{abstract}
In this paper work is carried out on modeling and analysis of compound tool for Vee-Cap component. Vee-cap (Novibra) part, which is used in AC motor, compressor, milling machines, industrial and marine generators, industrial fans, reserve power plants etc. $3 D$ Modeling of the compound tool component is carried out using Solid Edge v19. Structural analysis is carried out using ANSYS 16 for different angles $\left(0^{0}, 3^{0}\right.$, $4^{0}, 6^{0} \& 7^{0}$ ) of the component and the tool revel that increasing the tool angle the Stress and Strain are reduced for draw punch, draw tool and component, which gives better performance comparing to other designs. The induced plastic strain is more at die angle $0^{0}$ clearance i.e. $1.81 \%$ which shows that, component is failing due to excessive plastic deformation. The plastic strain for die angle $7^{0}$ is reduced by $\sim 65 \%$ and stress reduced by $\sim 64 \%$ compared to the other tool angles.
\end{abstract}

Keywords: Vee-Cap, Plastic Strain, Draw tool, punch, Deformation.

\section{Introduction}

Sheet metal is a simple metal formed into thin and flat pieces. It is one of the fundamental form used in metal working and can be cut and bend into many different shapes. Countless everyday objects are constructed with sheet metal. Thickness can vary significantly, extremely thin thicknesses are considered foil or leaf, and pieces thicker than $6 \mathrm{~mm}(0.25 \mathrm{inch})$ are considered plate. Sheet metal is available in flat piece or coiled strip. The coils are formed by running a continuous sheet of metal through a roll slitter. A progressive die performs a series of fundamental sheet metal operations at two or more stations during each press stroke in order to develop a work piece as the strip stock moves through the die. The work piece on progressive dies travels from one station to another, with separate operations being performed at each station. Usually the work piece is retained in the stroke until it reaches the final station, which cuts off the finished piece.

\section{Literature Review}

Jae Hun et al., described the development of computer-aided design of a very precise progressive die for lead frame of semiconductor chip. The approach to the system is based on knowledge-based rules. Knowledge for the system is formulated from plasticity theories, experimental results, and the empirical knowledge of field experts. This system has been written in Auto LISP using AutoCAD on a personal computer and the I-DEAS drafting programming Language, this based on knowledge-based rules, the system considers several factors, such as V-notches, dimple, pad chamfer, etc[1-3]. As forming processes and the die design system using $2 \mathrm{D}$ geometry recognition are integrated with the technology of process planning, die design, and $\mathrm{CAE}$ analysis, the standardization of die parts for lead frames requiring a high precision piercing process is possible. The die layout drawing generated by the die layout module is displayed in graphic form. The developed system makes it possible to design and manufacture lead frame of a semiconductor more efficiently [4-6]. Mayuri L1 et al., summarized as the work on design and analysis of sheet metal die for a flywheel cup. Flywheel cup is used in rotor of generator of internal combustion engine of automobiles. The design and manufacture of press tools, or punches and dies, is a branch of production technology that has extended into many lines of engineering manufacture over the past seventy years [7]. There is no doubt that the accuracy achieved by new ideas in design and construction applied by the press tool designer, coupled with increased speed and rigidity of the presses etc, used have all contributed toward maintaining this form of metal tooling well to the force as a means of obtaining pleasing, yet strong, durable articles that can withstand severe day-today usage[10-12].

As we have seen from the literature review, it becomes clear for us that a lot of work is carried out in sheet metal stamping using progressive tools. Even, though these tools are employed for draw operation, but no work is reported on draw operations using compound tools. Adding to this, analysis of any compound tool for draw operation is also not achieved. Hence we are motivated from this fact and we are using a compound tool manufactured for production of Vee-Cap component for analysis using ANSYS 16 software package [8,9]. 


\section{Model Of Compound Tool And Component}

The modeling of Vee-CAP die set is modeled by using Solid Edge v19 and analysis using ANSYS 16.

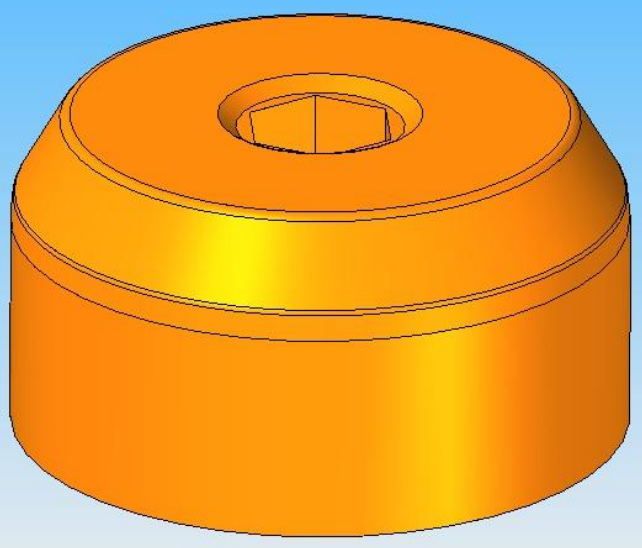

Figure 1. Model of Draw Punch

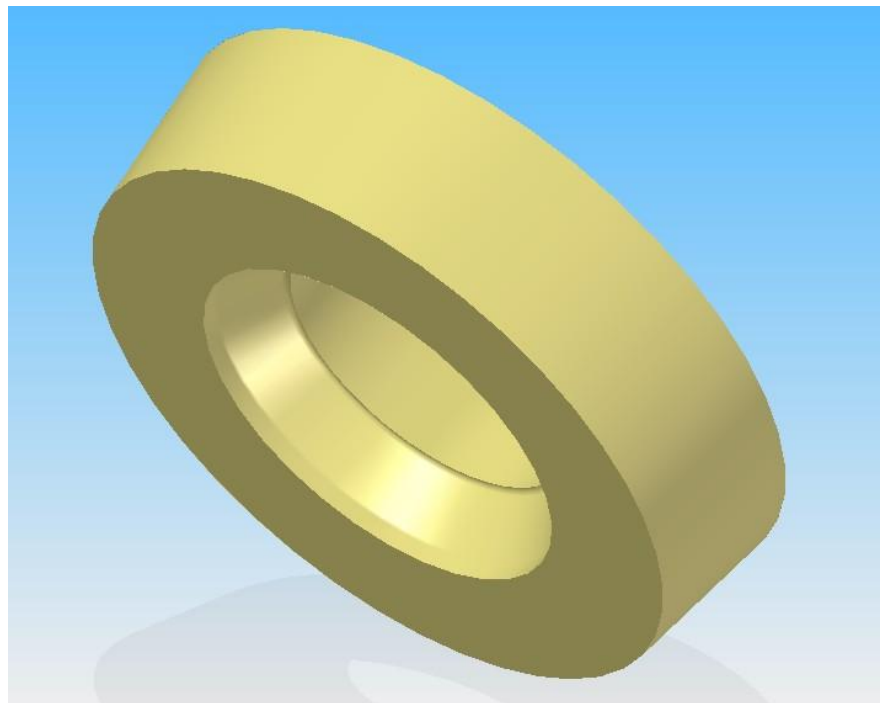

Figure 2. Model of Draw Die (seizing plate)

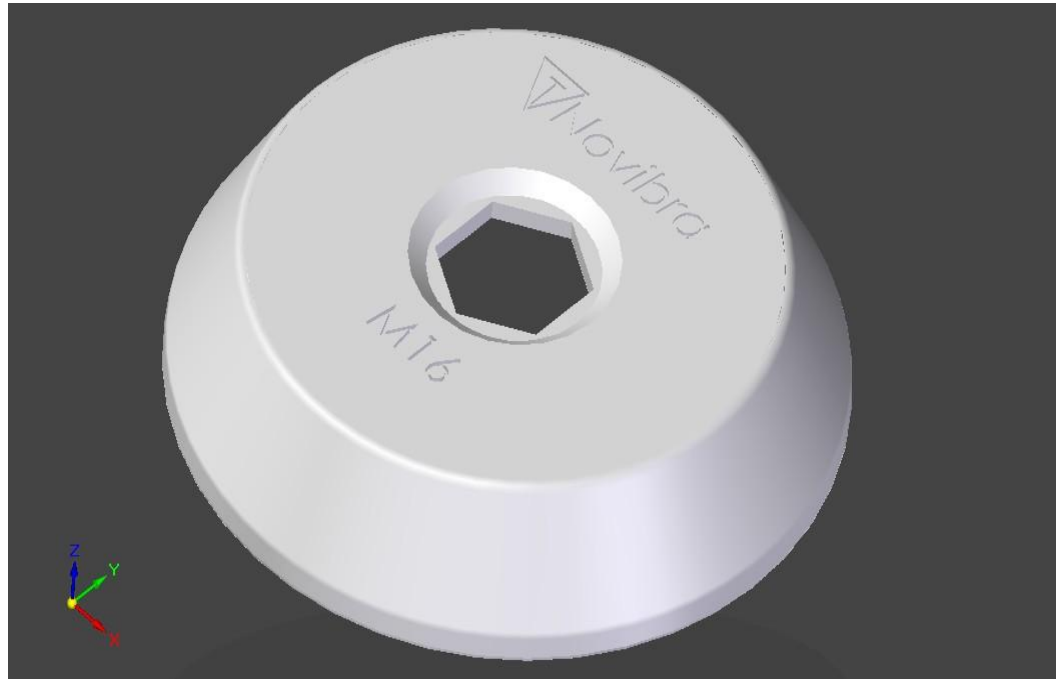

Figure 3: Model of Component (Vee-CAP) 


\section{Results And Discussions}

The following results such as stress, strain and displacement are obtained after simulation of forming die and punches with application of load. The non-linear material properties consider for component and the linear material properties consider for die and punch. Analyses is performed on draw die and draw punch which is using $\mathrm{HCHCr}$ (high carbon high chromium) and OHNS (oil hardened non-shrinkable steel) materials and for various angles clearance of die and punch are shown below.

Figure 3 shows displacement distribution of punch, it has observed that the maximum displacement developed is $0.14 \mathrm{~mm}$ at zero deg clearance. Figure 4 shows displacement distribution of Die, it has observed that the maximum displacement developed is $0.148 \mathrm{~mm} \sim 0.15 \mathrm{~mm}$ at zero deg clearance. Figure 5 shows VonMises Stress distribution of Punch, it has observed that the maximum Von-Mises Stress developed is $145 \mathrm{MPa}$ at zero deg clearance. Figure 6 shows Von-Mises Stress distribution of Die, it has observed that the maximum Von-Mises Stress developed is $162 \mathrm{MPa}$ at zero deg clearance.

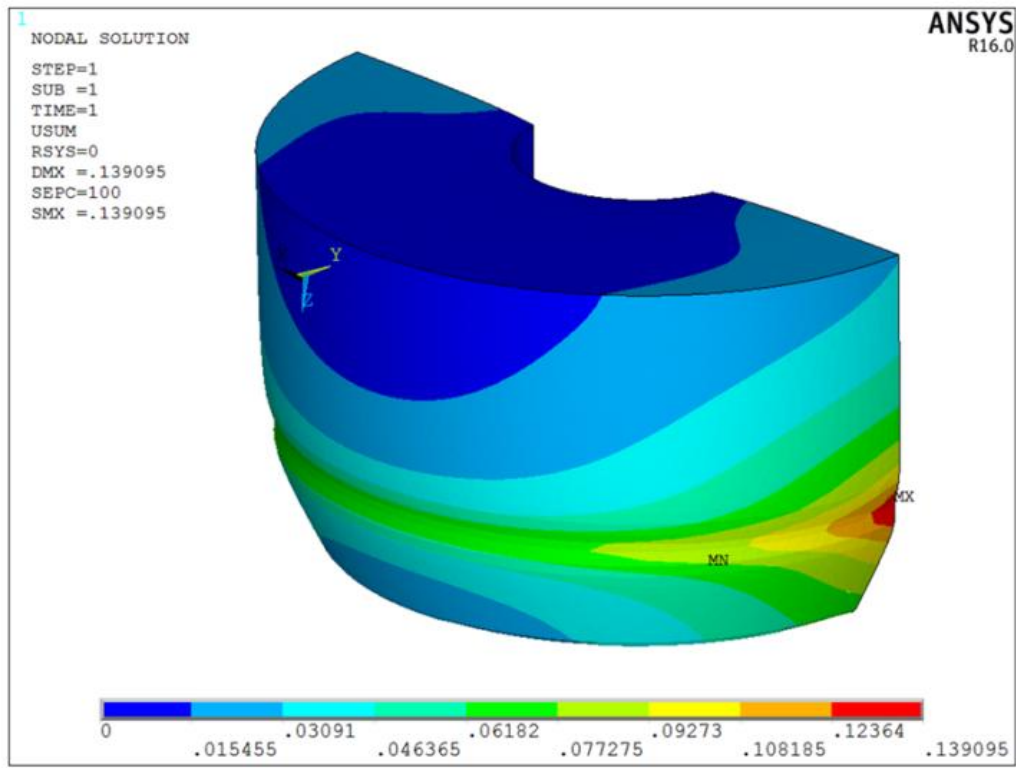

Figure 4. Displacement distribution on draw punch at zero deg

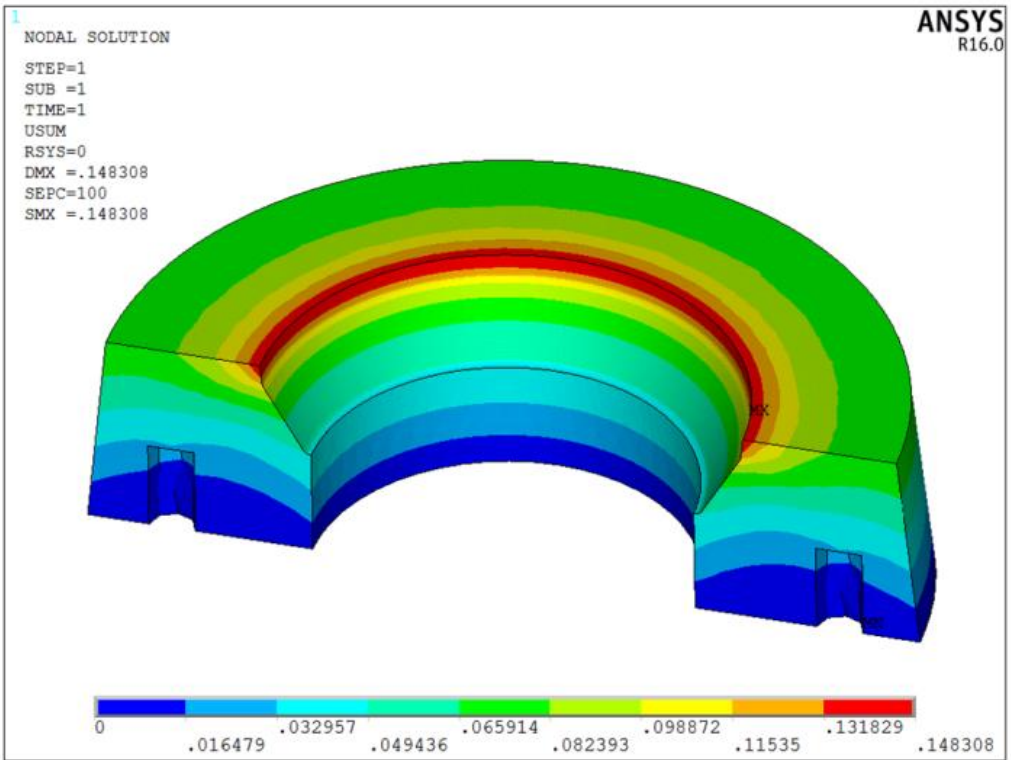

Figure 5. Displacement distribution on draw Die at zero deg 


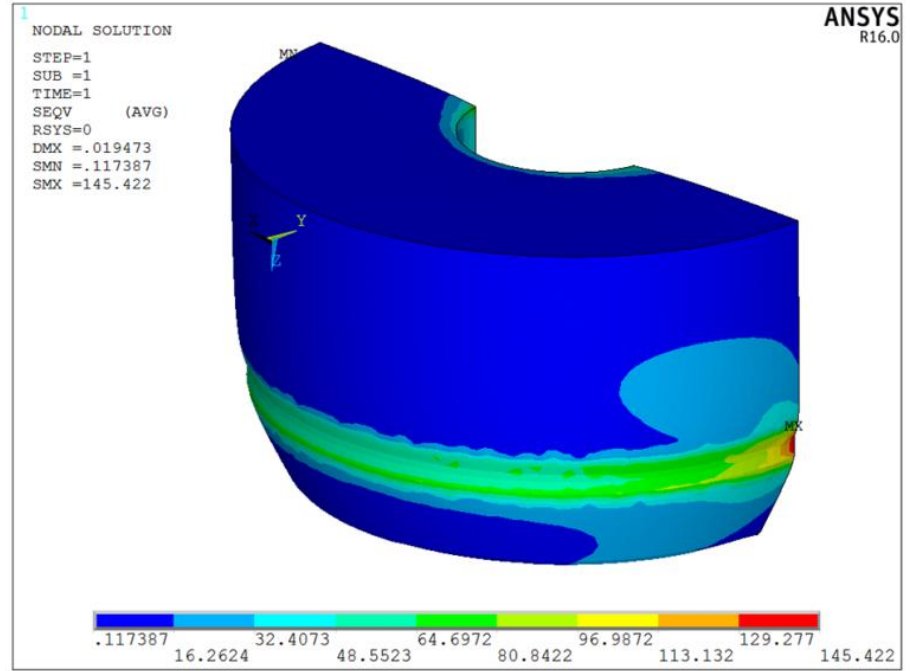

Figure 6. Von-Mises Stress distribution on Punch at zero deg.

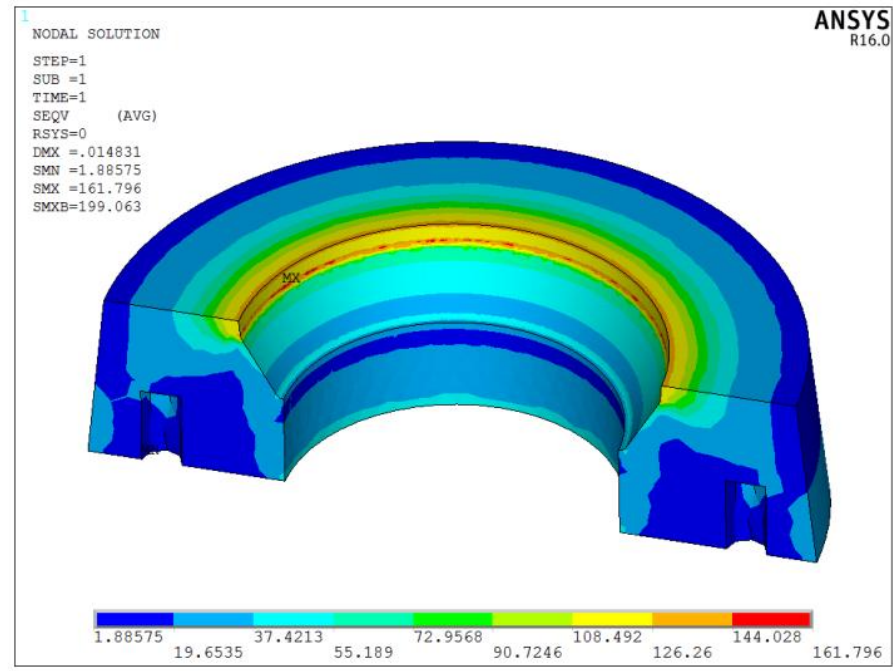

Figure 7. Von-Mises Stress distribution on Die at zero deg.

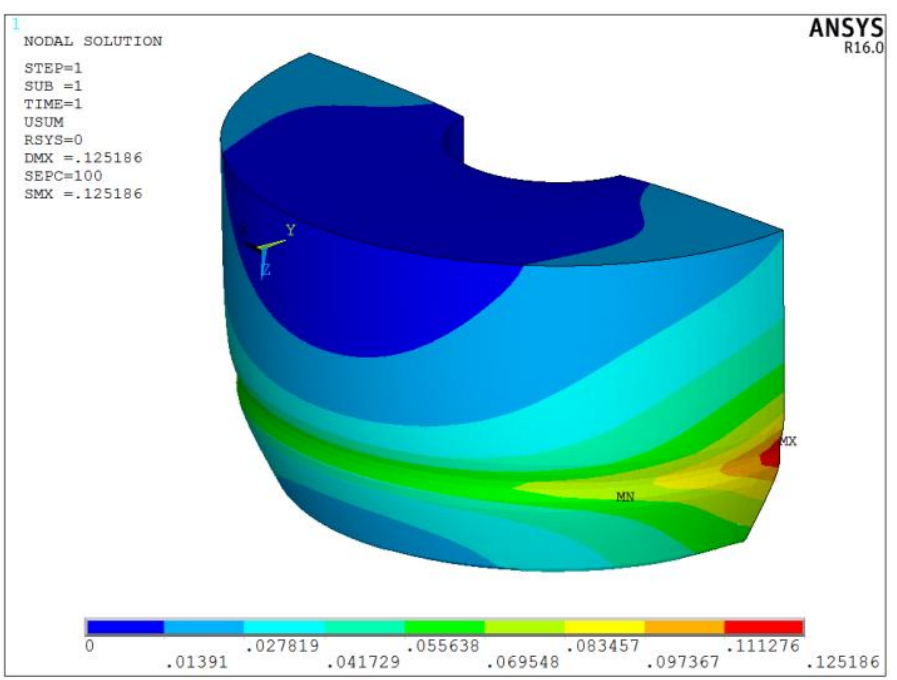

Figure 8. Displacement distribution on draw punch at $3 \mathrm{deg}$ 


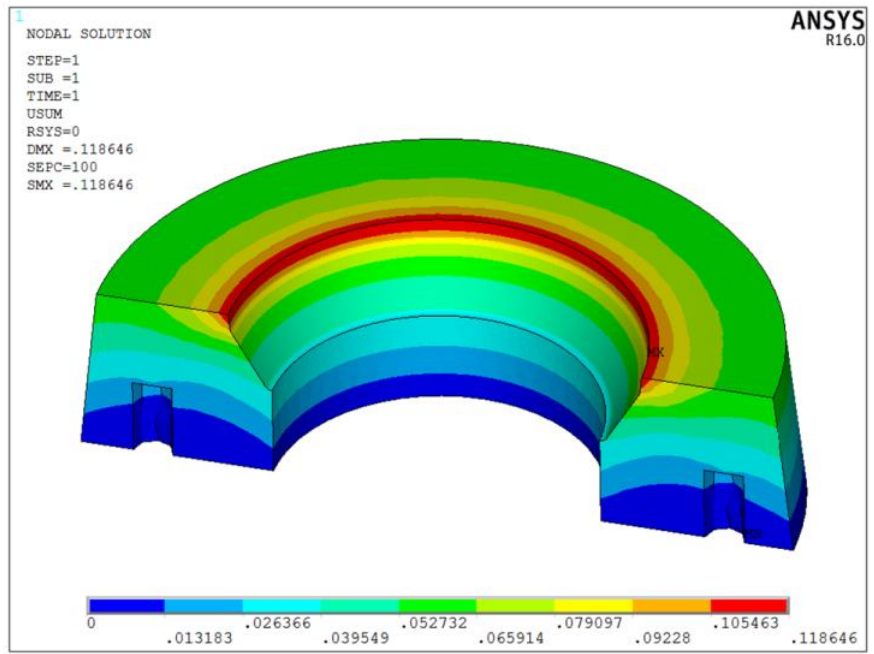

Figure 9. Displacement distribution on draw Die at $3 \mathrm{deg}$



Figure 10. Von-Mises Stress distribution on Punch at $3 \mathrm{deg}$.

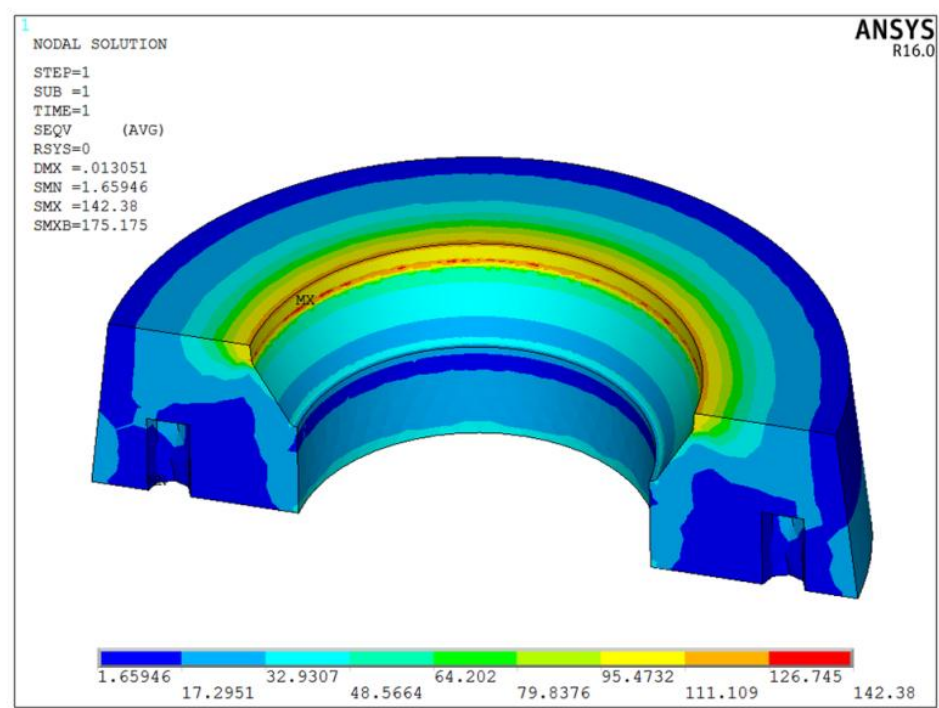

Figure 11. Von-Mises Stress distribution on Die at $3 \mathrm{deg}$ 
Figure 8 shows displacement distribution of Die, it has observed that the maximum displacement developed is $0.118 \mathrm{~mm}$ at $3 \mathrm{deg}$ clearance which less than zero deg. Figure 9 shows displacement distribution of Punch, it has observed that the maximum displacement developed is $0.125 \mathrm{MPa}$ at 3 deg clearance which less than ' 0 ' deg. Figure 10 shows Von-Mises Stress distribution of Die, it has observed that the maximum VonMises Stress developed is $142 \mathrm{MPa}$ at $3 \mathrm{deg}$ clearance which less than $0^{0}$.

\section{Conclusion}

From the Analysis we observed that, increasing the Die angle the Stress and Strain are reduced for draw punch, draw Die and component, gives better performance comparing to other designs. The induced plastic strain is more for zero deg clearance die i.e. $1.81 \%$ shows that, component is failing due to excessive plastic deformation. The plastic strain for die angle $3^{0}$ is reduced by $\sim 65 \%$ and stress reduced by $\sim 64 \%$ compared to the Die angle. The stresses and displacement induced in the die and punch is below the yield limit of the material for all clearance angles, hence design of punch and die is meeting the design requirements and safe.

\section{References}

[1] N. Jain, Progressive die sequence design and blank shape determination in stamping, The Ohio State University, 2003.

[2] K.K. Kumar, A. Srinath, M. Naveen, R. D, DESIGN OF PROGRESSIVE DIES, Int. J. Eng. Res. Appl. 2 (2012) 2971-2978.

[3] C. Mastanamma, K.P. Rao, M.V. Rao, Design and Analysis of Progressive Tool, Int. J. Eng. Res. Technol. 1 (2012) $1-10$.

[4] P.H. H Ameresh, Shankar, Progressive Tool Design and Analysis for 49 Lever 5 Stage Tools, Int. J. Comput. Trends Technol. 4 (2013) 2197-2206.

[5] J. Bhaskar, G.S. Prakash, Die design and analysis of progressive tool for can lid lever, Int. J. Res. Eng. Adv. Technol. $1(2013) 2-5$

[6] Y.. V.K. B. JAYA LAXMI, Design of Progressive Die Using Fe Analysis, Int. J. Res. Mod. Eng. Emerg. Technol. 2 (2014) 7-13.

[7] I. Rehaman, P.S. Reddy, M. Manoj, N.G. Murthy, Design and Analysis of Progressive Die for Chain Link Plate, Int. J. Sci. Eng. Adv. Technol. 2 (2014) 763-768.

[8] A. Afzal, Z. Ansari, A. Rimaz, F.M.K. Ramis, Parallelization Strategies for Computational Fluid Dynamics Software : State of the Art Review, Arch. Comput. Methods Eng. (2016). doi:10.1007/s11831-016-9165-4.

[9] Runa Nivea Pinto, Asif Afzal, Loyan Vinson Dsouza, Zahid Ansari, Computational Fluid Dynamics in Turbomachinery: A Review of State of the Art, Arch. Comput. Methods Eng. (2016). doi:10.1007/s11831-016-91752.

[10] Jyothi Bhaskar1, G Sathya Prakash2, "Die design and analysis of progressive tool for can lid lever"International Journal of Research in Engineering \&Advanced Technology, Volume 1, Issue 4, Aug-Sept,2013.

[11] Ch. Mastanamma1, K. Prasad Rao2, Dr. M.Venkateshwara Rao3, "Design and Analysis of Progressive die”, Vol. 1, Issue 6, Aug. 2012 IJERA

[12] Gashaw Desie1 and Yonas Mitiku Degu2 1, 2, Schoolof Mechanical and Industrial Engineering, Bahir Dar, Institute of Technology Bahir Dar University, Bahir Dar, Ethiopia " Progressive Die Design for Self Explosive Reactive Armor Holder (Case Study atBishoftu Motorization Industry-Ethiopia) ”, The International Journal Of Engineering And Science(IJES) ISSN (e): 2319 - 1813 ISSN (p): 2319 - 1805 